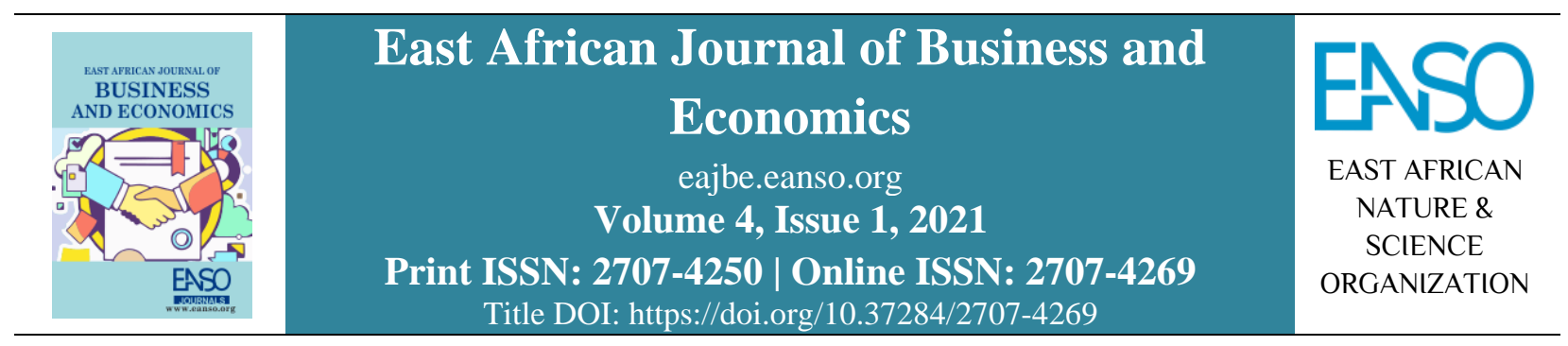

Original Article

\title{
COVID 19 The pandemic and Price Volatility: An Analysis of Hospitality Industry in Emerging Market Economy - Case Study of Tanzania.
}

\author{
Gloria A. Ntacho ${ }^{1 *} \&$ Dr. Seif Muba \\ ${ }^{1}$ Mzumbe University Tanzania, P. O. Box 1 , Morogoro, Tanzania. \\ *Correspondence ORCID ID: https://orcid.org/0000-0002-0506-3962; email: kaimuahmada@yahoo.com
}

Article DOI: https://doi.org/10.37284/eajbe.4.1.479

\section{Date Published: ABSTRACT}

23 November 2021 Hotel industries have had the most impact in most of the countries as people went into lockdowns and quarantines as a result of the COVID-19

Keywords: pandemic. The study aimed at assessing the degree of price change in relation to the profit of hotels before and during the COVID-19 pandemic.

COVID 19 The pandemic,

Price Volatility,

Hospitality Industry,

Emerging Market

Economy,

Tanzania,

Demand,

Supply Shifts.
Tanzania has been considered to represent developing countries that have taken a different course in a fight against the pandemic. Price movement determines the reaction from customers and therefore performance. This study prepared to identify the knowledge gap on how supply shocks affecting prices of hotels caused by COVID-19 pandemic that are beyond control, especially on a developing country like Tanzania could have on the performance of hotels and whether the recovery of such recession can be predicted in the short run. Movement in supply, demand and management strategies were regarded as an indicator of the direction of the performance of hotels in Tanzania pre and during the COVID-19 pandemic period. The study adopted both qualitative and quantitative analysis for a period of two years, 2019 to 2021, for a sample of two hotels in Dar es salaam which are 5- star hotels. Focus group discussion was used as a way to collect data along with secondary data. The regression analysis has been adopted to analyse secondary data after considering the correlation between variables in the study. Performance of hotels was measured using daily demand generated in pre and during the pandemic period against changes in prices influenced by COVID-19 pandemic. The study found out that the influence of price movement during the pandemic period was not significant enough to have led to the deteriorating performance of hotels in Tanzania. However, hotel performance deteriorated as a result of other contributing factors such as a fall in occupancy rate, lack of markets and increasing additional costs to fight against the pandemic, supply shocks which led to a fall in efficiency. It was evidenced that this was highly triggered by the overdependence of

34 | This work is licensed under a Creative Commons Attribution 4.0 International License. 
hotels on foreign markets. Travelling restrictions and lockdowns cultivated the deteriorating performance in hotels even though Tanzania never went into lockdown. However, hotel management adopted measures to contain the impacts through various ways, such as cutting down costs and revising prices. The study concluded and recommended that Tanzania hotels management should adopt flexible strategies on pricing that would accommodate unprecedented events that are beyond the control of the market forces (demand and supply). This would enable management to have decisions that reflect the condition in the country and not get influence from companies within the group situated in other countries.

\section{APA CITATION}

Ntacho, G. A., \& Muba, S. (2021). COVID 19 The pandemic and Price Volatility: An Analysis of Hospitality Industry in Emerging Market Economy - Case Study of Tanzania. East African Journal of Business and Economics, 4(1), 34-45. https://doi.org/10.37284/eajbe.4.1.479

\section{CHICAGO CITATION}

Ntacho, Gloria A. \& Seif Muba. 2021. "COVID 19 The pandemic and Price Volatility: An Analysis of Hospitality Industry in Emerging Market Economy - Case Study of Tanzania”. East African Journal of Business and Economics 4 (1), $34-45$. https://doi.org/10.37284/eajbe.4.1.479.

\section{HARVARD CITATION}

Ntacho, G. A., \& Muba, S. (2021) "COVID 19 The pandemic and Price Volatility: An Analysis of Hospitality Industry in Emerging Market Economy - Case Study of Tanzania”, East African Journal of Business and Economics, 4(1), pp. 34-45. doi: 10.37284/eajbe.4.1.479.

\section{IEEE CITATION}

G. A. Ntacho, \& S. Muba, "COVID 19 The pandemic and Price Volatility: An Analysis of Hospitality Industry in Emerging Market Economy - Case Study of Tanzania", EAJBE, vol. 4, no. 1, pp. 34-45, Nov. 2021.

\section{MLA CITATION}

Ntacho, Gloria A. \& Seif Muba. "COVID 19 The pandemic and Price Volatility: An Analysis of Hospitality Industry in Emerging Market Economy - Case Study of Tanzania”. East African Journal of Business and Economics, Vol. 4, no. 1, Nov. 2021, pp. 34-45, doi:10.37284/eajbe.4.1.479.

\section{INTRODUCTION}

Novel coronavirus, currently COVID-19 pandemic was first identified in Wuhan City in China in December 2019 and gradually spread throughout the world. Until February 2021, confirmed cases of COVID -19 worldwide accumulates to 104,031,036 out of which 75,867,883 have recovered and 2,250,245 have died, affecting 221 countries and territories in the world (WHO, 2020). In Tanzania, the COVID-19 pandemic first case was identified on March 162020 in Arusha, a tourist region, according to the Tanzania Ministry of Health report (2020). There have been 509 COVID-19 confirmed cases and 21 deaths until January 2020 (WHO, 2021). COVID - 19 the pandemic has not only had a significant and disastrous impact on social life but also has affected the world economy. The trend has been observed historically for the hotel sector to be affected by the pandemics such as the Black Death (1346-1353), SARS (2002-2004), and the Ebola virus (2014-2016) (Roy, 2020).

Basing on Tanzania's economic report produced by World Bank (2020), the tourism sector has been severely affected by COVID-19 resulting in most hotels catering for international visitors suspending their operations to reduce costs and reduce contagion. This was supported by a forecast that revenue would fall by $80 \%$ or more in 2020 and recovery in the following year.

Hotels have faced impact from different angles and one of them being the ability to control price so as 
to influence customers during the period of the pandemic. Deficiency in demand brought about unexpected income risk and high economic uncertainty (Guerri et al., 2020).

This study is prepared to identify the knowledge gap on how supply shocks affecting prices of hotels caused by COVID-19 pandemic that are beyond control, especially on a developing country like Tanzania could have on the performance of hotels and whether the recovery of such recession can be predicted in the short run. Movement in supply, demand and management strategies will be regarded as an indicator of the direction of the performance of hotels in Tanzania pre and during the COVID-19 pandemic period.

According to the Keynesian theory of supply shocks as argued by Baqaee and Farhi (2020), unexpected event such as (natural hazards and pandemics) in the economy that changes the supply of a product or service results in a sudden change in price and creates a demand greater than the shocks themselves. The theory explains the mechanism on how unexpected event creates a temporary recession as a result of a fall in demand, employment, output and inflation, but due to fiscal and monetary policies by the government and market mechanism, the equilibrium point is once again restored at full employment level and at higher aggregate demand but with a different equilibrium price.

It is now difficult to estimate whether the shock caused by the pandemic will be effective enough to bring back efficient response after recession since the extent of the negative shocks have not been determined and governments are not sure of the policies to be adopted to restore efficiency (Veronica, 2020).

The major purpose of the study was to understand the degree of influence COVID- 19 the pandemic has had on price in relation to the profit of hotels in Tanzania. Through evaluating the trend of demand, supply, and management strategies of hotels between pre and during the pandemic period. This was performed by understanding demand and supply shifts and management actions taken by hotels which will enable hotel management to understand how to cope with uncertain events in the future. This study covers the gap and answers the questions below.

$R Q$ 1: How has demand shifts affected hotel revenue before and during the pandemic Period?

$R Q$ 2: How has supply shocks affected hotel costs before and during the pandemic Period?

RQ3: What is the management reaction during The pandemic period to maintain performance?

\section{LITERATURE REVIEW}

\section{Theoretical Review}

\section{Demand and Supply Theory}

Along the demand curve, movement in prices at the market is determined by forces of demand and supply other factors being held constant. In times of natural hazards and outbreaks income of an individual will only spend it on a luxurious service of its disposable income after spending the basic needs (Giddings, 1890). Contrary to the Law, the price of hotel services will not be determined by the forces of demand and supply since they are all affected at the same time. The Law of demand and supply as explained by Giddings (1890), will not hold at times of the pandemic such as the COVID19 period. According to the study done by Bagaee and Farhi (2020) on Supply versus Demand during COVID-19 recessions explained that during this time of the pandemic, the world is expecting negative supply and demand shocks which in turn would cause a downward movement in real GDP but changes in price would be minimal. 


\section{Keynesian Theory of Unemployment}

According to Keynes (1936), when an economic slump set in for any reason, the fear among businesses and investors tends to become selffulfilling and can lead to a sustained period of depressed economic activity and unemployment. As economic distress manifests itself at the time of the pandemic, employers will find means to contain their costs since revenue will be falling. Turnover of employees will tend to be high as a way to reduce costs and at the same time comply with measures of social distancing. As chaos theory (Connelly, 1996) suggest on the butterfly effect, that one state of a deterministic nonlinear system can result in large differences in a later state. So was the effect of the pandemic in relation to unemployment.

\section{Cost Volume Profit Analysis (CVP)}

Most hotels in the world use CVP analysis to determine their targeted profit and break-even point so as to allow proper allocation of their funds projection of required quantity and price is efficient when there are no other factors that could hinder proper planning such as the emergence of natural hazards and the pandemic (Pellinen, 2003). Due to the ongoing COVID-19 pandemic, hotels have experienced an un-precedent low level of occupancy rates which in turn may result in a drop in prices, pressing down the average daily rates (O’Neill \& Matilla, 2010).

\section{Empirical Review}

Crozier (2020) in his report of the COVID-19 impact on hotel values, explained that it is in this period of extreme volatility and uncertainty that hasty and potentially costs decisions are made. Based on the trend, it is expected for GDP in different countries to deteriorate over time. In support of the argument, Khan and Khan (2020 in their research explained that demand for food, medical aid, and other essential goods may increase; however, the demand for non-essential goods will be less. Services offered by hotels are luxurious services not essential for survival. Therefore, COVID-19 reduces demand for the tourism industry and causes panic among the public (Bakari and Rosbi, 2020).

\section{Conceptual Framework}

Figure 1: COVID-19 Impact on Price setting and Hotel Performance

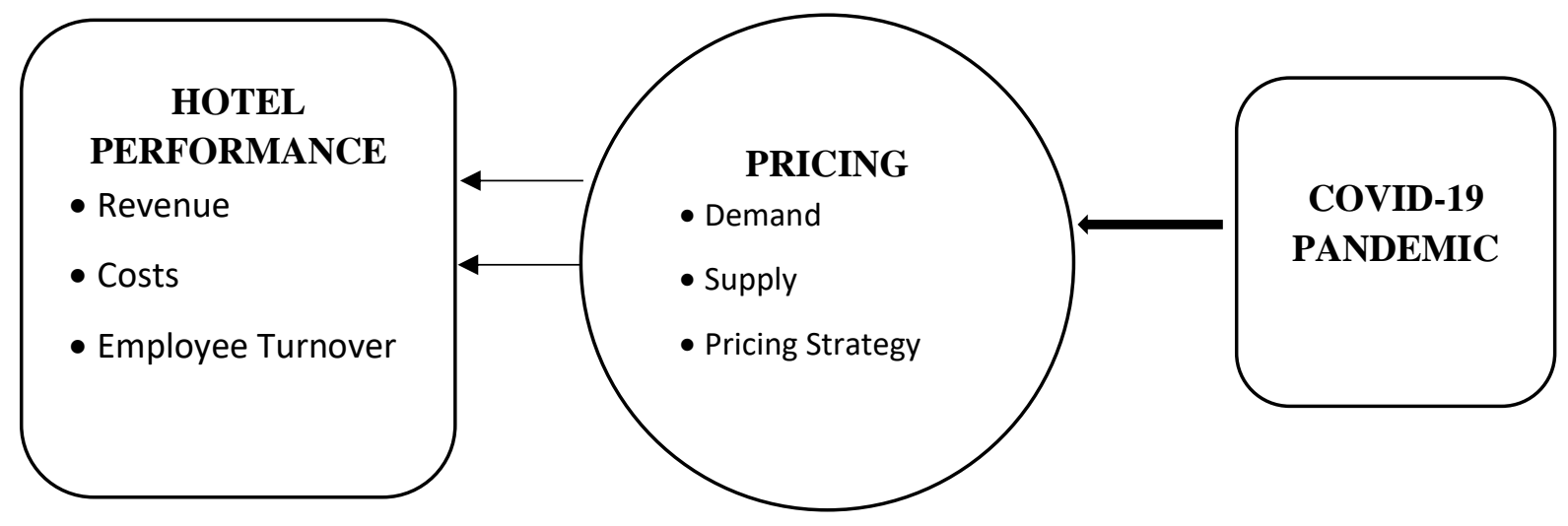

\section{METHODOLOGY}

\section{Research Design}

The study employed both quantitative and qualitative research techniques where focal point discussion was used to collect qualitative data. The targeted population of the study were 30 hotels in Dar es salaam Tanzania which are 3-5 stars where businessmen would go for meetings, investment prepositions and tourism. The population was 
chosen to understand the performance of big hotels in developing countries who seem to be great contributors of revenue to the government in terms of tax revenue and investment in bonds and due to fact hotels in generation foreign currency in the country.

\section{Selection Criteria}

In this study, hotels with the following qualities were included; hotels that are privately owned or shared ownership with the government, hotels that are monitored with government laws and regulations and hotels that are not necessarily managed in Tanzania but also in other countries such as being part of group companies or branches where the head office is not resident in Tanzania. The basis for this selection was to understand the intervention of the government and stakeholders' decisions in determining the performance of Tanzania during times of COVID-19 pandemic.

\section{Development Model}

This study used a regression model with lagged explanatory variables as a method of analysis because variables influence others with a time lag. The analysis showed the relationship that exists between the growth of the COVID-19 pandemic and the performance of hotels over time while showing the economic implications of such a relationship.

$Y_{t}=\infty^{+} p X_{t-h}+\mu_{t}$

The regression analysis model represents the overall model that was used.

Table 1: Characteristics of hotels
- $\mathrm{Y}(\text { demand })_{\mathrm{t}}=\infty+\oint_{0} \mathrm{X}(\mathrm{rev})_{1}+\oint_{1} \mathrm{X}(\mathrm{Rev})_{\mathrm{t}-1}+\oint_{2}$ $\mathrm{X}(\operatorname{Rev})_{\mathrm{t}-2}+\ldots \ldots \rho_{\mathrm{n}} \mathrm{X}\left(\operatorname{Rev}_{\mathrm{n}-1}+\mu\right.$

- $\mathrm{Y}(\text { supply })_{\mathrm{t}}=\infty+\hat{\wp}_{0} \mathrm{X}($ Cost $)+\mathrm{p}_{1} \mathrm{X}(\text { Cost })_{\mathrm{t}-1}+\mathrm{p}_{2}$ $\mathrm{X}(\text { Cost })_{\mathrm{t}-2}+\ldots \operatorname{p}_{\mathrm{n}} \mathrm{X}(\text { Cost })_{\mathrm{n}-1}+\mu$

- $\mathrm{Y}(\mathrm{mgt} \text { decs })_{\mathrm{t}}=\infty+\oint_{0} \mathrm{X}\left(\mathrm{NP}_{1}+\oint_{1} \mathrm{X}(\mathrm{NP})_{\mathrm{t}-1}+\oint_{2}\right.$ $\mathrm{X}(\mathrm{NP})_{\mathrm{t}-2}+\ldots \hat{p}_{\mathrm{n}} \mathrm{X}(\mathrm{NP})_{\mathrm{n}-1}+\mu$

Where;

$\mathrm{Y}($ Demand $)=$ Dependent variable measuring the daily number of customers of hotels pre and during the pandemic period; $\mathrm{X}$ (rev) = Independent variable measuring daily revenue over before and during COVID-19 period. In the model above, $\boldsymbol{p}$ represent the slope coefficient of the independent variable over time for each of the independent variables that is demand, supply and management decision. $\infty=$ represents a constant variable for each of the models, and $\mu$ is an error term for all other variables that we have not taken into account.

\section{PRESENTATION OF FINDINGS}

The hotels used in the study are five-star hotels offering accommodation, conference halls for holding events restaurant services for food and beverage to both local and foreign customers. Dar es Salaam Serena hotel has 74 employees distributed among different departments such as finance and accounts, front office, kitchen, room service (housekeeping), and storekeeping. It has 230 rooms for single and double beds.

\begin{tabular}{lll}
\hline Details & Hotel 1 & Hotel 2 \\
\hline Number of rooms & 230 & 180 \\
Average price per room in USD & 157 & 162 \\
Number of employees & 74 & 53 \\
Class of hotel & 5-star hotel & 5-star hotel \\
Nature of ownership & Group of companies in different & Group of companies in \\
& countries & different countries \\
\hline
\end{tabular}


Descriptive Statistics of the Variables Under Study

The total number of observations is 1488 collected on a daily basis from January 12019 to January 13 2021 for the two hotels. From the results presented in Table 2 showing descriptive results, values of skewness and Kurtosis have fallen with the standard range implying the presence of normal distribution. When results of skewness of data lie between -2 to $2+$ and Kurtosis lies between -7 to 7+ implies that data under study are normally distributed about its mean. Gan Soh Fuey \& Noraini Idris (2017). Refer to the Table 2 below:

Table 2: Descriptive Statistics of The Variables Under Study

\begin{tabular}{lllll}
\hline Variables & Mean & Std. Dev. & Skewness & Kurtosis \\
\hline Demand & 7.061 & 3.402 & 0.0712 & 0.1207 \\
Supply & 3.797 & 2.631 & 0.0582 & 0.0628 \\
Mgt strategy & 7.934 & 2.950 & 0.0639 & 0.0835 \\
Revenue & 9.164 & 8.961 & 0.1250 & 0.2547 \\
Costs & 1.566 & 1.271 & 1.2500 & 0.2630 \\
Turnover & 2.826 & 3.075 & 0.2350 & 0.0576 \\
\hline
\end{tabular}

Source: Field data 2021

\section{Correlations Test among Variables}

Data findings demonstrated to have a positive relationship between demand and revenue per room (0.5182). This implies that an increase in demand would result in a corresponding increase in the revenue of rooms and that decrease in demand would lead to a decrease in the profit of a room. However, a negative relationship exists between supply shocks and costs at 0.0495 at a 5\% significant level, implying that a decrease in the rate of turnover of employees would result in an increase in hotel costs and vice versa. Management action relates positively to the rate of turnover of employees at hotels at 0.1164 , which implies that an increase in management actions would have a corresponding increase effect on employee turnover rate. See the Table 3 below.

Table 3: Correlation matrix of variables

\begin{tabular}{lllllll}
\hline Variables & $\mathbf{1}$ & $\mathbf{2}$ & $\mathbf{3}$ & $\mathbf{4}$ & $\mathbf{5}$ & $\mathbf{6}$ \\
\hline 1. Demand rate & 1 & & & & & \\
2. Supply rate & $0.0949^{*}$ & 1 & & & & \\
3. Management Strategy & $0.516^{*}$ & 0.0226 & 1 & & & \\
4. Revenue & $0.5182^{*}$ & $0.1473^{*}$ & $0.1460^{*}$ & 1 & & \\
5. Cost & $0.0544^{*}$ & 0.0418 & -0.0495 & -0.0468 & 1 & \\
6. Employee rate & $0.2762^{*}$ & 0.1164 & 0.0958 & $0.4703^{*}$ & 0.0188 & 1 \\
\hline
\end{tabular}

* Signiant at 0.05

Test of Normality from residual (Normal Distribution)

In this study, we have measured the degree of probability of distribution of random variable about its mean and the height and sharpness of the central peak relative to that of the standard bell curve (Hald, 1981). From Table 2, skewness was determined for every variable. Figure 1 shows the residual representing all other variables and how distributed they are. Basing on our study, below findings shows how data were tested for normal distribution and 
East African Journal of Business and Economics, Volume 4, Issue 1, 2021

Article DOI: https://doi.org/10.37284/eajbe.4.1.479

whether the resultant mean is representative of the data.

\section{Multicollinearity Test of Variables}

Basing on our study, results show all variables do not show any indicator of multicollinearity as the mean VIF of 1.25 is below 5 and reciprocal of individual variables are below 1 such as price is 0.7268 , turnover of employees is at 0.7330 and occupancy is at 0.9901 (See Table 4).

Table 4: Multicollinearity through Variance Inflation Factor (VIF)

\begin{tabular}{lll}
\hline Variables & VIF & 1/VIF \\
\hline Demand rate & 1.38 & 0.7268 \\
Supplies rate & 1.36 & 0.7330 \\
Management action & 1.01 & 0.9901 \\
Mean VIF & 1.25 & \\
\hline
\end{tabular}

Source: Field data 2021

\section{Model Specification of Variables}

Results of the study show that the demand rate has $29.7 \%$ ability to explain revenue per room considering other factors in the model being constant and standard error of $1.97 \%$ representing other variables not in the model. The supply rate has a 50\% ability to explain costs of the hotel when considered along with other factors at a standard error of $91.8 \%$ representing other factors not in the study. Management action rate on the other hand has $87.2 \%$ ability to explain the rate of stay of employee turnover in the hotel at a standard error of 6\%. See Table 5 below:

Table 5: Summary of Models Specifications

\begin{tabular}{llll}
\hline Model Summary & & & \\
\hline Models & R-square & Adjusted R- square & STD Error \\
\hline Revenue & 0.297 & 0.2961 & 0.0197 \\
Cost & 0.501 & 0.314 & 0.9186 \\
Employee turnover & 0.872 & 0.853 & 0.0603 \\
\hline
\end{tabular}

\section{Regression Results}

The P-value of the results in Table 6 explains the following on the variables. For results of P-value below 5\% significant level implies that variables have statistical power to explain corresponding dependence variable. It basically expresses the strength of evidence against the null hypothesis (Jian, 2020). From the results in Table 6, results show that all variables have reflected a $\mathrm{p}$-value below $5 \%$ significant level.

Table 6: Shows Regression Results.

\begin{tabular}{llllll}
\hline Independent variables & constant & Std Error & P-Value & \multicolumn{2}{c}{ Confidence interval } \\
\cline { 5 - 6 } & & & & Lower limit & Upper limit \\
\hline Demand rate & 0.4585 & 0.0197 & 0.000 & 0.4198 & 0.4972 \\
Supply rate & -0.1445 & 0.0226 & 0.000 & -0.189 & -0.1001 \\
Management action & 0.1959 & 0.0452 & 0.000 & 0.1071 & 0.2847 \\
\hline
\end{tabular}

Source: Field data 2021 
From the results presented in Table 6 above shows that an increase in a unit (USD) of daily demand per room for a hotel without a change in the rate of employee turnover and daily cost rate will tend to add revenue per room by 0.4585 times. However, results show that an increase in unit supply rate when maintaining the same daily demand per room and without change in management action will result in a fall in daily hotel costs by 0.0927 . A unit increase in management strategy keeping constant demand and supply rate would result in an increase in the rate of employee turnover stay by 0.21638 .

\section{Degree of Price Change in Relation to Profit of Hotels before and During COVID-19 Period}

The price of Hotel 1 in each room had an average of USD 191 in January 2019, while in 2020, each room had an average price of USD 157, marking a $21 \%$ decrease from 2019. In 2019 the annual profit was 481. 09 Million, while in 2020, the annual loss was 1.150 billion SHS. The loss was shown to have been significantly high. While in 2020, the price of each room in Hotel 2 was 162 USD, while in 2019, the price in each room was USD 195. The average price was equivalent to a decrease of $16.9 \%$. See the Table 7 below:

Table 7: degree of price and profit change of hotels

\begin{tabular}{|c|c|c|c|c|c|c|c|}
\hline \multirow[t]{2}{*}{ Variables } & \multicolumn{2}{|l|}{ Price } & \multicolumn{2}{|c|}{ Profit /(loss) } & \multicolumn{2}{|c|}{ \% change } & \multirow[b]{2}{*}{ P-Value } \\
\hline & $2019 / 20$ & $2020 / 21$ & $2019 / 20$ & $2020 / 21$ & $\begin{array}{l}2019 / 20 \\
\text { (price) }\end{array}$ & $\begin{array}{l}2020 / 21 \\
\text { (profit) }\end{array}$ & \\
\hline Hotel 1 & 191 & 157 & 481 & (1.150) Billion & $-21 \%$ & $-139 \%$ & 0.00026 \\
\hline Hotel 2 & 195 & 162 & (24) & (206) & $-16.9 \%$ & $-758 \%$ & \\
\hline Total & 386 & 319 & (457) & (1.356) billion & $37.9 \%$ & $-897 \%$ & \\
\hline
\end{tabular}

Price \& profit/loss $=$ USD in millions

\section{Qualitative Findings}

Focus Group Discussion (FGDs) and in-depth interviews were employed to gather and analyse data for report writing. A random selection of participants who met the criteria was performed. The first FGD was for Junior staff with 2-3 years of working experience and the second FGD was for senior staff with experience of four years and above regardless of their departments. Each FGD was comprised of 6 members. Participants interviewed were from the following areas: Waiters, housekeeping attendants, hotel chefs and Finance department members.

\section{Situation of Prices and Profit of Hotels before COVID-19 Pandemic}

It was explained that the hotel could accommodate many customers' foreigners and locals, mostly during the period of March to November (the season that was considered as the business season). As the occupancy level of customers increases, so is the increase in profit.

"I can say that hotel gets profit if accommodates many customers since they pay as they stay. Taking into consideration that whatever they consume they have to pay" (FGD- a junior from Hotel 2)

Moreover, before COVID-19, hotels could host different events as a means to promote revenue and this included executive meetings, wedding ceremonies, seminars and workshops, summit meetings and entertainments events. However, revision of prices over time was not done often unless a major change in the market has forced the hotel to revise their prices. Special offers in price were given to customers who came in larger groups, wedding events and the ones who would stay longer. 
East African Journal of Business and Economics, Volume 4, Issue 1, 2021

Article DOI: https://doi.org/10.37284/eajbe.4.1.479

"Before the epidemic of COVID-19, many events were performed in hotels and they were given offers as motivations to maintain clients and there was no periodically revision of price and profit could be observed easily" (senior FGD Hotel 1).

Table 8: Situation of prices and profit of hotels before COVID-19 in Hotels

\begin{tabular}{llll}
\hline Theme & FGD-1 & FGD 2 & Informant \\
\hline $\begin{array}{l}\text { There was no much change in prices but profit was always } \\
\text { changing because we were able to collect a big amount of money } \\
\text { per day }\end{array}$ & $\mathrm{V}$ & $\mathrm{V}$ & $\mathrm{V}$ \\
\hline $\begin{array}{l}\text { Price before COVID-19 had no significant change since market } \\
\text { rates were stable however, change in profit was observed. }\end{array}$ & $\mathrm{V}$ & $\mathrm{V}$ & $\mathrm{V}$ \\
\hline $\begin{array}{l}\text { The hotel was able to generate profit because it was in a good } \\
\text { position to offer variety of options for profit generation }\end{array}$ & $\mathrm{V}$ & \\
\hline $\begin{array}{l}\text { I cannot comment anything about the hotel price and profit which } \\
\text { hotel. }\end{array}$ & $\mathrm{V}$ & \\
\hline
\end{tabular}

V-responses, $\mathrm{V}=$ response

Situation of Prices and Profit of Hotels during COVID-19 Period

During fieldwork, some participants from different groups expressed their views on the degree of change in prices and profit of hotels that, prices during COVID-19 pandemic period were not changed in an actual sense as a way to motivate customers, special prices were offered to accommodate few customers that showed up. When the customers did not come in as they used to be, automatically the profit dropped tremendously because the welfare of hotels depends on customers.

"Prices during COVID-19 pandemic period were not changed in the actual sense as a way to motivate customers; special prices were offered to accommodate few customers that showed up. But because the customer could not come in as it used to be automatically the profit was low" (FGD- a junior from Hotel 2)..

Table 9: Situation of prices and profit of hotels before COVID-19 in Hotels

\begin{tabular}{llll}
\hline & FGD-1 & FGD 2 & Informant \\
\hline $\begin{array}{l}\text { Prices during COVID-19 was not changed as a way to motivate } \\
\text { customers; special prices were offered to accommodate a few } \\
\text { customers that showed up. But because the customer could not } \\
\text { come in as it used to be, automatically the profit was proper }\end{array}$ & $\mathrm{V}$ & $\mathrm{V}$ \\
\hline $\begin{array}{l}\text { No change was noticed in terms of prices rather inflow of } \\
\text { customers was not as in previous periods, and this resulted in low } \\
\text { profit }\end{array}$ & $\mathrm{V}$ & $\mathrm{V}$ \\
\hline $\begin{array}{l}\text { profit was dramatically dropped because we get profit basing on } \\
\text { clients who are seeking services from our hotels, clients are few }\end{array}$ & $\mathrm{V}$ \\
\hline $\begin{array}{l}\text { Profit generated from hotels is very low compared to the past } \\
\text { because hotels were still figuring out ways to restore trust to their } \\
\text { customers and ensure their safety against the the pandemic. }\end{array}$ & \\
\hline \begin{tabular}{l} 
V-responses, V response \\
\hline
\end{tabular} & \\
\hline
\end{tabular}




\section{DISCUSSION}

Quantitative findings were analysed using Stata version 13 whereby ANOVA was used to present data in the form of graphs and tables, while qualitative data were analysed thematically. The study findings realised both hotels accommodate more foreign customers compared to local customers and their profit depends mostly on foreign customers. Once foreigners stop coming, there will be a fall in the revenue of the hotels. This was evidenced during the COVID-19 pandemic, whereby travelling restrictions were imposed by different countries and others went into lockdown, and hotels failed to get customers. This is in line with the study carried out by Polemis (2020) on the impact of COVID-19 on hotel performance.

The study findings revealed COVID-19 had a big negative impact on profit-driven about with many factors with less influence being out of price changes triggered by the pandemic. This was evidenced by the prices and profits before the emerging of COVID-19 and during the COVID-19 pandemic. The study noted that in 2019 Hotel 1 had an average profit of 481 million while Hotel 2 had a profit of 500 million. However, there were minor changes in price per room in both hotels.

Only a $20 \%$ decrease was observed from the price of USD 191 from Hotel 1, while a 16\% decrease in price from USD 195 in 2019 was evidenced in Hotel 2 . The above results were in agreement with a study which was carried out in Hong Kong by Wu et., al, (2020) on Fluctuations in Hong Kong Hotel Industry Room Rates under the 2019 Novel Coronavirus (COVID-19), where results indicated that room rates across hotels in Hong Kong were primarily influenced by holidays and festivities prior to COVID-19, whereas rates tended to decline after the outbreak.

Based on study findings, it was identified that both hotels continued to employ the same pricing strategies during the period of the pandemic which in turn they did not prove to be efficient. Pricing strategies employed included, provision of discounts and offers, lower prices when booking is done at the earliest or awarded after winning a prize a discount in room price. Such strategies were identified to have not been efficient because customers were not in a position to respond to the offers as people were concerned with health rather than taking advantage of the pricing discount offered.

The research findings of the study also reflected a major fact that during the period of the pandemic, forces of demand and supply could not be used to determine prices at the market as to how it was normally expected.

The study findings realised that hotel costs rose during the period of the pandemic due to additional costs that needed to be incurred to support the fight against the pandemic. This included costs on sanitisers, disinfectants and detergents, facial masks, gloves, renovation of hotels to ensure social and physical distancing, hire of trainers on hygiene, increase in water supply and infrared thermometers. Reduction of employees' salary was a mechanism to contain hotel costs during the time of the pandemic to avoid severe impact in terms of hotel performance.

\section{CONCLUSION}

From the study, it has been evidenced there was a minimal degree of changes in prices triggered by the COVID-19 pandemic and that market forces could not determine the price due to supply shocks resulting in to fall in demand. This, in turn could not have a direct impact on the profit of Hotels. However, Hotel performance deteriorated as a result of factors such as a fall in occupancy rate, rate of stay, increased costs and management action. Tanzania hotels have not invested much in improving local markets; this is why the performance of hotels could not be supported by local markets during the pandemic period. 
Moreover, despite the fact that most hotels have resumed their operations, hotels have not been able to recover their economic positions because no sufficient orientation and sensitisation on how best we can fight against the COVID-19 pandemic and make people feel safe to be in Tanzania.

\section{Recommendations}

The study recommends hotels in Tanzania have in place mitigation plans on how to cope with unexpected events such as outbreaks and Epidemics, natural hazards and political changes that could affect the hotel industry. Hotels in Tanzania should improve local markets and invest in promoting local tourism in the country to avoid over-dependency during times of need like what happened during the pandemic period. This will enhance sustainability during a period of fluctuation in the foreign market.

Moreover, Tanzania hotels should have in place research and training departments that would be responsible for looking for markets, advancement in technology to promote markets and understanding regulations and legal matters affecting the hospitality industry. This would enable management to have decisions that reflect the condition in the country and not get influence from companies within the group situated in other countries.

\section{REFERENCES}

Bakar, N. A., \& Rosbi, S. (2020). Effect of Coronavirus disease (COVID-19) on tourism industry. International Journal of Advanced Engineering Research and Science, 7(4), 189193.

Baqaee, D., \& Farhi, E. (2020). Supply and demand in disaggregated keynesian economies with an application to the covid-19 crisis (No. w27152). National Bureau of Economic Research.
Connelly, T. J. (1996). Chaos theory and the financial markets. Journal of financial planning, 9(6), 26.

Crozier, T. (2020, Nov 10). The COVID Impact on Hotel Values. CNRE Hotels. https://www.cbrehotels.com/en/research/articles /the-covid-impact-on-hotel-values.

Dwyer C and Horney J. (2014). Validating Indicators of Disaster Recovery with Qualitative Research. PLOS Currents Disasters. Edition 1.

Economic and Social Research Foundation (2020 May). Rapid Social Economic Impact Assessment of COVID 19 in Tanzania. Report.

Giddings, F. H. (1890). PRINCIPLES OF ECONOMICS. By Alfred Marshall, Professor of Political Economy in the University of Cambridge. MacMillan \& Co., London and New York, 1890. Vol. I, pp. xxviii, 754. The ANNALS of the American Academy of Political and Social Science, 1(2), 332-337

Gössling, S., Scott, D., and C. Hall, C. H. (2020). The pandemics, tourism and global change: a rapid assessment of COVID-19, Journal of Sustainable Tourism. 1-20.

ICAO (2018). Travel and Tourism a Force for Good in the World, Accessed November,7,2018,www.icao.int/Meetings/iwaf 2018/Documents/Travel\%20and\%20Tourism.p df (accessed March 31 2020)

Keynes, J. M. (1936). The supply of gold. The Economic Journal, 46(183), 412-418.

Khan, D. \& Khans, L. Y. (2020). The Economic Impact of COVID-19 on Developing Countries. IPS News. http://www.ipsnews.net/2020/04/theeconomic-impact-of-covid-19-on-developingcountries/ 
O'Neill, J. W., \& Mattila, A. S. (2010). Hotel brand strategy. Cornell hospitality quarterly, 51(1), 27-34.

Roy, S. (2020). Economic impact of COVID-19 tpandemic. Technical report. https://www.researchgate.net/profile/ShohiniRoy/publication/343222400_ECONOMIC_IMP ACT_OF_COVID19_PANDEMIC/links/5fa1e11e92851c14bc036 d68/ECONOMIC-IMPACT-OF-COVID-19PANDEMIC.pdf

Pellinen, J. (2003). Making price decisions in tourism enterprises. International Journal of Hospitality Management, 22(2), 217-235.

Polemis, M., \& Soursou, S. (2020). Assessing the impact of the COVID-19 pandemic on the Greek energy firms: an event study analysis. Energy Research Letters, 1(3), 17238.

Vallecillo, G., Perelló, R., Güerri, R., Fonseca, F., $\&$ Torrens, M. (2021). Clinical impact of COVID-19 on people with substance use disorders. Journal of Public Health, 43(1), 9-12.

World Bank. (2021). The Human Capital Index 2020 Update: Human Capital in the Time of COVID-19.

World Health Organization. (2020). Mental health and psychosocial considerations during the COVID-19 outbreak, March 182020 (No. WHO/2019-nCoV/MentalHealth/2020.1). World Health Organization.

Wu, F., Zhang, Q., Law, R., \& Zheng, T. (2020). Fluctuations in Hong Kong hotel industry room rates under the 2019 Novel Coronavirus (COVID-19) outbreak: Evidence from big data on OTA channels. Sustainability, 12(18), 7709.

WHO. (2021). COVID-19 Status: Tanzania. https://covid19.who.int/region/afro/country/tz
Shapiro, Matthew D. (1991) "Are Cyclical Fluctuations In Productivity Due More To Supply Shocks Or Demand Shocks?," American Economic Review, 1987, v77(2), 118-124.

Veronica, G. (2020) Macroeconomic Implications of COVID-19: Can Negative Supply Shocks Cause Demand Shortages?

Gan Soh Fuey \& Noraini Idris. (2017) “Assessing the Validity of the Elements for Pre-Service Mathematics Teacher Education Curriculum" International Journal of Academic Research in Business and Social Sciences, 2017, Vol. 7, No. 12 ISSN: 2222-6990 